\title{
Water transport in an epoxy-phenolic coating
}

\author{
S. Morsch ${ }^{\mathrm{a}, *}$, S. Lyon ${ }^{\mathrm{a}}$, P. Greensmith ${ }^{\mathrm{b}}$, S.D. Smith ${ }^{\mathrm{c}}$, S.R. Gibbon ${ }^{\mathrm{d}}$ \\ a Corrosion and Protection Centre, School of Materials, The University of Manchester, The Mill, Sackville Street, Manchester, M13 9PL, UK \\ ${ }^{\mathrm{b}}$ Material Science Centre, School of Materials, The University of Manchester, Manchester, M13 9PL, UK \\ ' Akzo Nobel Chemicals BV, Supply Chain, Research E' Development, P.O. Box 10, 7400 AA Deventer, Netherlands \\ d Akzo Nobel, Supply Chain, Research E Development, Stoneygate Lane, Felling, Gateshead, Tyne and Wear, NE10 0JY, UK
}

\section{A R T I C L E I N F O}

\section{Article history:}

Received 25 May 2014

Accepted 15 August 2014

Available online 30 August 2014

\section{Keywords:}

Epoxy-phenolic

Water uptake

Infrared spectroscopy

\begin{abstract}
A B S T R A C T
Thermoset coatings commonly rely on high cross-linking density to provide enhanced barrier properties. Hence it is surprising that for the industrial epoxy-phenolic network investigated, equilibrium moisture uptake is found to increase with respect to cure time, i.e., with greater cross-linking. Molecular interactions between absorbed water and the resin are characterised using infrared spectroscopy, and water uptake is correlated to network polymer features such as polarity and free volume.
\end{abstract}

(c) 2014 Elsevier B.V. All rights reserved.

\section{Introduction}

Epoxy resins are widely used in the fields of aerospace engineering [1-3], marine coatings [4], microelectronics [5,6], and packaging [7] in the form of paints [8], adhesives [9] and composites $[10,11]$. Such resins are known to confer excellent mechanical properties [12,13], chemical resistance [14], anti-corrosive properties [15-17] and thermal stability $[18,19]$ due to their highly cross-linked nature. Nonetheless, for every application reliant on the mechanical or barrier properties of an epoxy resin, moisture absorption is a key consideration in the evaluation of long-term performance. Significant water uptake is characteristic of epoxy coatings, and has been demonstrated to induce swelling [20,21], hydrolysis [22,23], crazing [24], cracking [25], plasticisation [26] and lowering of the $T_{\mathrm{g}}[27,28]$. Yet, to date, a comprehensive mechanistic understanding of the water sorption process remains elusive.

Moisture uptake by epoxy resins has previously been investigated using techniques such as positron annihilation lifetime spectroscopy (PALS), NMR, FTIR, fluorescence, dielectric spectroscopy and gravimetric analysis. The development of PALS has been instrumental in defining the role of free volume contained within epoxy resins. Despite some apparently contradictory results, a picture has emerged where resins containing a greater proportion of free volume absorb more water when polarity is controlled [29-33]. However, equilibrium water uptake is primarily determined by the hydrogen bonding capability of the network

\footnotetext{
* Corresponding author. Tel.: +44161306 2914.

E-mail address: suzanne.morsch@manchester.ac.uk (S. Morsch).
}

(polarity) [34-38]. Meanwhile, water in epoxy resins has long been established by FTIR techniques to exist in both a free form (not interacting with the resin), and also in a bound state, hydrogen bonded to polymeric sites [39-43]. This dual nature for sorbed water is supported by an abundance of evidence from simulation [44], dielectric measurements [45-47], and fluorescence [48]. NMR studies have further found that water in resins may be subcategorized according to mobility [49,50]. Soles et al. [32] have suggested a model encompassing these results, where water transport in epoxies occurs via the free volume, allowing access to neighbouring polymeric hydrogen bonding sites.

The majority of the aforementioned studies have focussed on model epoxy-amine resins. Little attention has been given to industrial systems, which typically comprise a complex mixture of resin and cross-linker, solvents, and numerous additives to promote wetting of the substrate, drying and curing. Typical additives have been shown to be hygroscopic, so that water uptake may be dependent on their concentration and distribution rather than bulk polymeric properties [51,52]. Furthermore, relatively few studies have reported on water uptake for epoxy-phenolic systems, despite their prevalence in food contact and beverage can-coating applications, i.e., where the applied film is submerged throughout its lifetime [53,54]. Suzuki et al. [55,56] measured free volume for a range of epoxy-phenolic resins using the PALS technique, and found a direct correlation between free volume and water uptake, however the effect of resin polarity was neglected. Conversely, Zhang et al. [15] examined two epoxy-phenolic systems and reported greater water sorption for the resin containing less free volume, so concluded that water uptake was dependent only on polarity. Numerous 2D ATR-FTIR investigations have also 
confirmed the presence of free and bound water for epoxy-phenolic formulations [37,57-59].

In the present study, the effect of free volume on moisture uptake is evaluated using time-resolved FTIR for an industrial epoxy-phenolic coating. In order to control polarity and isolate the effect of cross-linking density (closely related to free volume), variable cure times are used, since alternative strategies such as varying the cross-linker to epoxy ratio, or else the chemical structure of the cross-linker, frequently constitute a variation in resin polarity.

\section{Experimental}

\subsection{Sample preparation}

Electrolytic chrome-coated steel pieces $\left(4 \mathrm{~cm}^{2}\right)$ were degreased by rinsing in ethanol (Fisher Scientific, >99\%). Thin films of epoxy-phenolic Vitalure 345 Lacquer (AkzoNobel Packaging Coatings, Elbeuf, France) were then spin cast onto the steel pieces at $2000 \mathrm{rpm}$ for $30 \mathrm{~s}$ (Headway Research Inc., 1-10,000 rpm). Samples were cured by placing in an oven maintained at $200^{\circ} \mathrm{C}$ for a prescribed time interval (5-30 $\mathrm{min})$.

\subsection{Film characterisation}

In order to assess film thickness, samples were sputter coated with gold (Polaron E5100), mounted at $90^{\circ}$ in araldite resin (10:1 Araldite AY 103-1:Aradur HY 951, Huntsman) and polished to expose cross-sections. These were then carbon coated (Edwards E306) and measurements were taken using a scanning electron microscope (Zeiss Evo 50).

Sessile contact angle analysis was performed at $20^{\circ} \mathrm{C}$ using video capture apparatus (FTA188 Tensiometer, FTA Europe) and $5 \mu \mathrm{L}$ of high purity water.

For modulated DSC, epoxy-phenolic coatings were mechanically removed from the substrate, and 1-3 mg placed in aluminium pans. DSC curves were obtained over a temperature range of $-90^{\circ} \mathrm{C}$ to $300^{\circ} \mathrm{C}$ under nitrogen using a heating/cooling rate of $3{ }^{\circ} \mathrm{C} \mathrm{min}-1$ with a modulation period of $\pm 1^{\circ} \mathrm{C} \mathrm{min}^{-1}$ (Q100 modulated DSC, TA Instruments).

Infrared spectra are the result of 16 accumulations collected in reflectance mode using an FTIR spectrometer (Spectrum 2000, Perkin Elmer), operating at $4 \mathrm{~cm}^{-1}$ resolution across the $700-7000 \mathrm{~cm}^{-1}$ range. In order to assess water uptake, saturated $\mathrm{NaCl}$ solution was warmed to $50^{\circ} \mathrm{C}$ and placed in recrystallizing dishes at the bottom of the sample chamber, which was fitted with a portable temperature and humidity data logger (Lascar Electronics). Humidity was allowed to equilibrate for $20 \mathrm{~min}$ prior to collection of the background spectrum (electrolytic chrome-coated steel substrate). Within $5 \mathrm{~min}$ of salt solution insertion, humidity within the sample chamber was measured to be $80 \pm 1 \% \mathrm{RH}$, and remained stable throughout the experiment. FTIR spectra were gathered continuously for $60 \mathrm{~min}$ following insertion of the coated sample. For peak-fitting of the acquired spectra Gaussian functions were fitted using a least squares fitting technique based on a Levenberg-Marquardt algorithm (Fitky 0.9.8 Software v.2 [60]).

Gravimetric uptake was performed using free-standing films acquired by cathodic delamination. Cured, spin cast coatings were removed from tin-plated steel by application of $+3 \mathrm{~V}$ ( $\mathrm{vs}$. $\mathrm{Ag} / \mathrm{AgCl}$ reference electrode) for $5 \mathrm{~h}$. After removal from the substrate, the films were soaked in deionised water and dried in a desiccator for 2 weeks. The thus-obtained free standing films yielded unchanged ATR-IR spectra and contact angles on both sides, indicating that the polymer film was unaffected by the delamination procedure. For gravimetric uptake, films were accurately weighed, placed in the FTIR chamber under raised humidity for $60 \mathrm{~min}$ (i.e., under
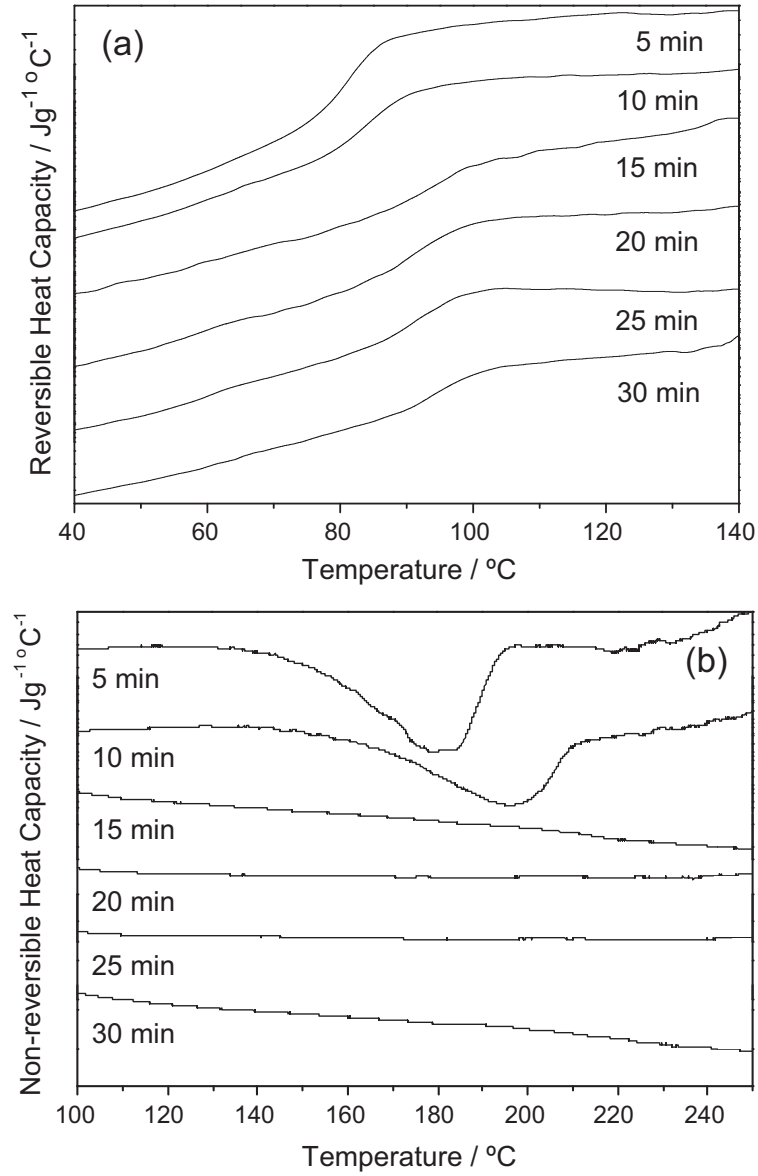

Fig. 1. Modulated DSC (a) reversible and (b) non-reversible heat capacity traces for epoxy-phenolic thin films cured for 5-30 min at $200^{\circ} \mathrm{C}$.

conditions identical to those described for time-resolved FTIR analysis) and then re-weighed.

Atomic force microscopy images were obtained using a Multimode 8 (Bruker, Santa Barbara) operating in Peakforce Nanomechanical Mode using a Tap525 probe (Bruker, nominal spring constant $200 \mathrm{~N} / \mathrm{m}$, nominal resonance frequency of $525 \mathrm{kHz}$ ). Deflection sensitivity was calibrated against a sapphire reference, and a relative calibration technique was performed using polystyrene to ascertain tip radius and spring constant. Measurements were made using a custom made humidity chamber. Air was bubbled through saturated salt solution into the chamber to achieve $70 \% \mathrm{RH}$. The DMT modulus and topography signals were then continuously recorded for $2 \mathrm{~h}$. All images were gathered using the same probe, operating at a $0.5 \mathrm{~Hz}$ scan rate. Mean values quoted are for 512 sample points per 512 scan lines over $100 \mu \mathrm{m}^{2}$.

\section{Results}

\subsection{Coating characterisation}

DSC analysis of the epoxy-phenolic films yielded increasing $T_{\mathrm{g}}$ values and broadening transitions as a function of cure time, indicating enhanced cross-linking, Fig. 1 and Table 1 . In addition, the excess cure detected in the irreversible trace (from residual reactants, at $180-200^{\circ} \mathrm{C}$ ) was attenuated with respect to cure time, until no signal was detected for cure times exceeding $10 \mathrm{~min}$, Fig. 1. Further evidence for the cross-linking reaction was gathered by SEM analysis, which revealed initial shrinkage with curing, followed by gradual increase in coating thickness when the reaction is close to 
Table 1

Film thickness, static water contact angle and $T_{\mathrm{g}}$ data for Vitalure 345 spin-coated onto electrolytic chrome coated steel, cured at $200{ }^{\circ} \mathrm{C}$ for variable times. Errors correspond to 1 S.D. for 40 measurements.

\begin{tabular}{cclc}
\hline Cure time $/ \mathrm{min}$ & Film thickness $/ \mu \mathrm{m}$ & Contact angle $/{ }^{\circ}$ & $T_{\mathrm{g}} /{ }^{\circ} \mathrm{C}$ \\
\hline 5 & $9.2 \pm 0.6$ & $84 \pm 2$ & 81.4 \\
10 & $7.4 \pm 0.6$ & $84 \pm 2$ & 83.9 \\
15 & $9.0 \pm 0.5$ & $83 \pm 2$ & 90.5 \\
20 & $10.4 \pm 0.5$ & $84 \pm 1$ & 89.5 \\
25 & $10.4 \pm 0.5$ & $83 \pm 2$ & 90.9 \\
30 & $11.0 \pm 1.3$ & $83 \pm 1$ & 91.9 \\
\hline
\end{tabular}

completion ( $>10$ min cure time), Fig. 2 and Table 1 . Taken alongside the consistent mass measured for the coating $\left(1.8 \pm 0.1 \mathrm{mg} \mathrm{cm}^{-1}\right.$ regardless of cure time) this is in keeping with resin densification during initial curing stages, followed by the expected reduction in density (and hence increasing free volume) for highly cross-linked samples $[61,62]$. Finally, static water contact angles remained constant with respect to cure time, confirming that no change in resin polarity accompanied curing, Table 1 .

\subsection{Water uptake by FTIR}

In order to assess the effect of cross-linking on water uptake, the prepared epoxy-phenolic films were placed under raised humidity and FTIR spectra were continuously monitored for $60 \mathrm{~min}$, Fig. 3. Infrared absorbance in the fingerprint region $\left(700-2000 \mathrm{~cm}^{-1}\right)$ remained unaffected by exposure to a high humidity ( $80 \% \mathrm{RH}$ ) environment, thereby confirming that no disruption of macromolecular structure occurs due to hydrolysis reactions. During exposure, an incremental increase of the broad absorbance centred around $3416 \mathrm{~cm}^{-1}$ was observed, Fig. 3. This band is attributed to the $\mathrm{OH}$ stretch of hydroxyl groups within the epoxy-phenolic coating, with the $\mathrm{OH}$ stretch absorbance of water superimposed upon it [63]. Moisture uptake is therefore directly proportional to the total absorbance increase in this region, and was quantified by integration of the $3416 \mathrm{~cm}^{-1}$ band at each time point. For direct comparison of water sorption between samples, this value was normalised to the unchanged area of the $\mathrm{CH}$ stretch band (centred on $2892 \mathrm{~cm}^{-1}$ ) and the initial reading (at 0-0.4 min) was set to zero, Fig. 4. It can be seen that the more highly cross-linked samples cured for prolonged periods of time absorb more water. This is supported by gravimetric measurements for water uptake by free-standing films, Fig. 5.

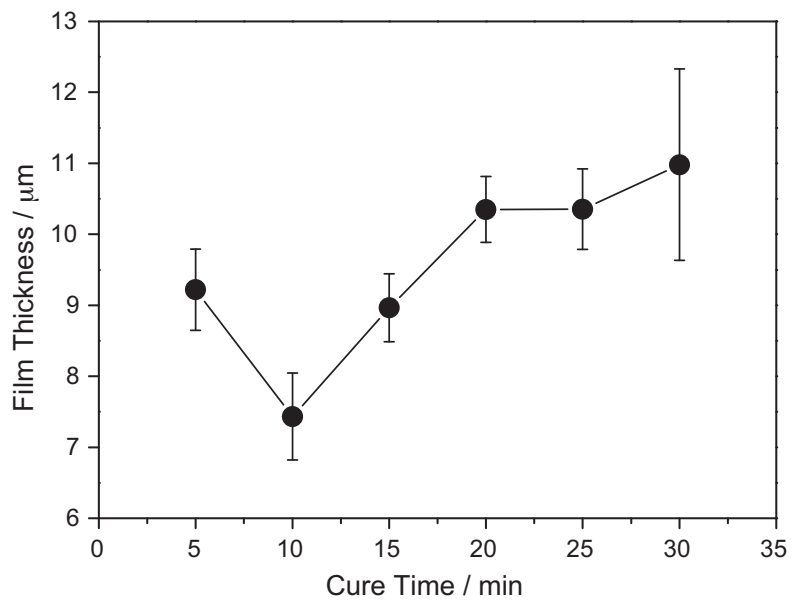

Fig. 2. Epoxy-phenolic resin film thickness (from SEM cross-section analysis) as a function of cure time at $200^{\circ} \mathrm{C}$. Errors correspond to 1S.D. for 40 individual measurements.

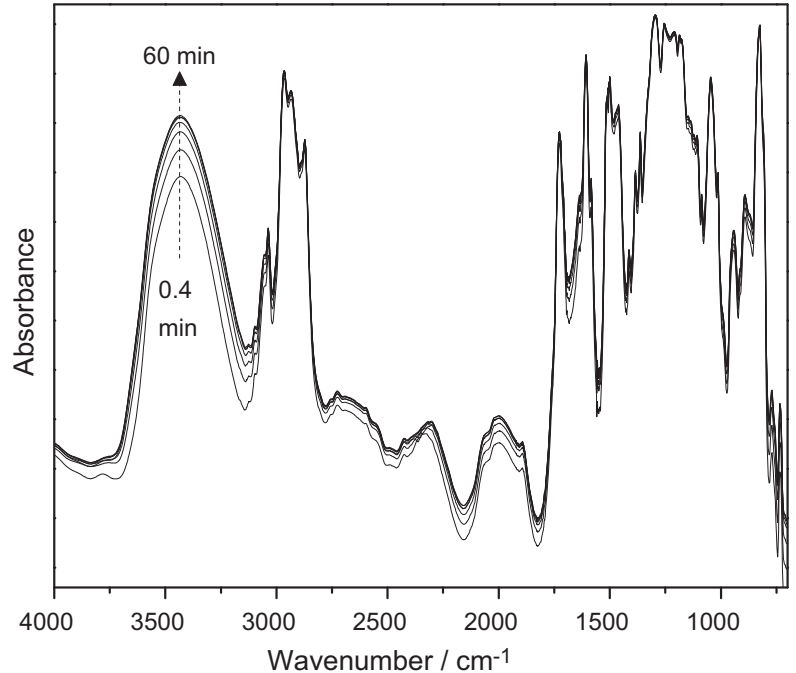

Fig. 3. Mid-FTIR spectra of a 30 min cured sample of spin-coated Vitalure 345 after exposure to an $80 \% \mathrm{RH}$ environment for $0.4,10,20,30,40,50$ and $60 \mathrm{~min}$.

Subtraction of the initial FTIR spectrum (taken at 0-0.4 min exposure time) yields difference spectra corresponding to the absorbed water, Fig. 6. Characteristic mid infrared peaks ( $\mathrm{OH}$ bend at $1635 \mathrm{~cm}^{-1}$ and $\mathrm{OH}$ stretch at $3416 \mathrm{~cm}^{-1}$ ) were reproduced in this manner for all samples. Furthermore, close inspection of the $\mathrm{OH}$ stretch absorbance band reveals a complex envelope with a fine structure, indicating that absorbed water exists in a variety of environments within the epoxy-phenolic films, Fig. 7. For comparison, the spectrum for humid air is also given (corresponding to the steel substrate under $80 \% \mathrm{RH}$, with the spectrum obtained under ambient conditions subtracted). The difference in peak position, width and intensity provides further evidence that the measured difference spectra are due to sorbed water, rather than any fluctuation in humidity.

Notable features of the $\mathrm{OH}$ stretch band for sorbed water include a sharp absorbance in the $3600-3700 \mathrm{~cm}^{-1}$ region, characteristic of dangling $\mathrm{OH}$ bonds uninvolved in hydrogen bonding, Fig. 7. In contrast, absorbance in the lower wavenumber region around $3100-3250 \mathrm{~cm}^{-1}$ is indicative of strongly hydrogen bonded water;

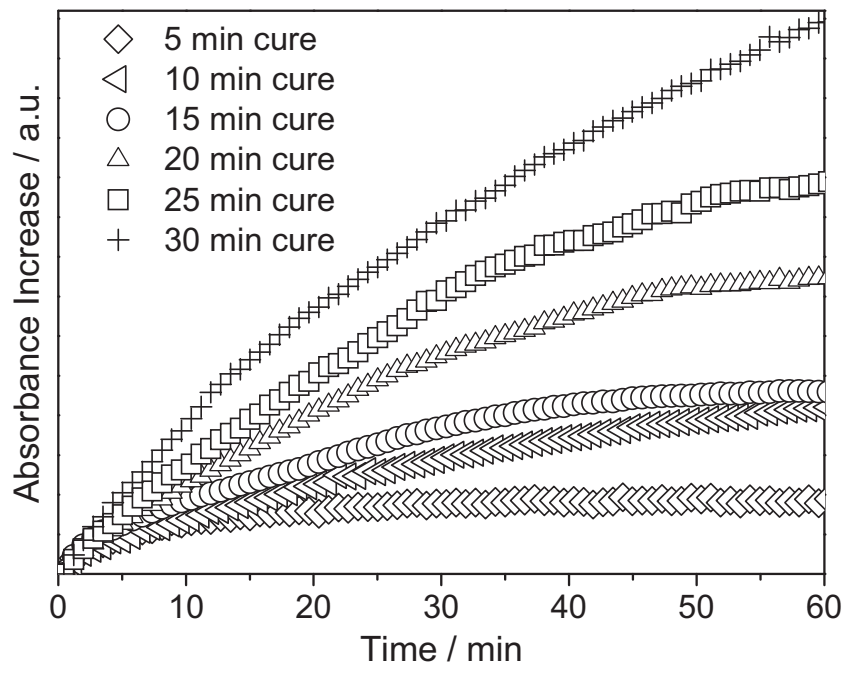

Fig. 4. Absorbance increase of the $\mathrm{OH}$ stretch band (normalised to the $\mathrm{CH}$ stretch band) as a function of exposure time to $80 \%$ RH for epoxy-phenolic coating cured for $5,10,15,20,25$ and $30 \mathrm{~min}$. Each point represents the mean value obtained from five experiments. 


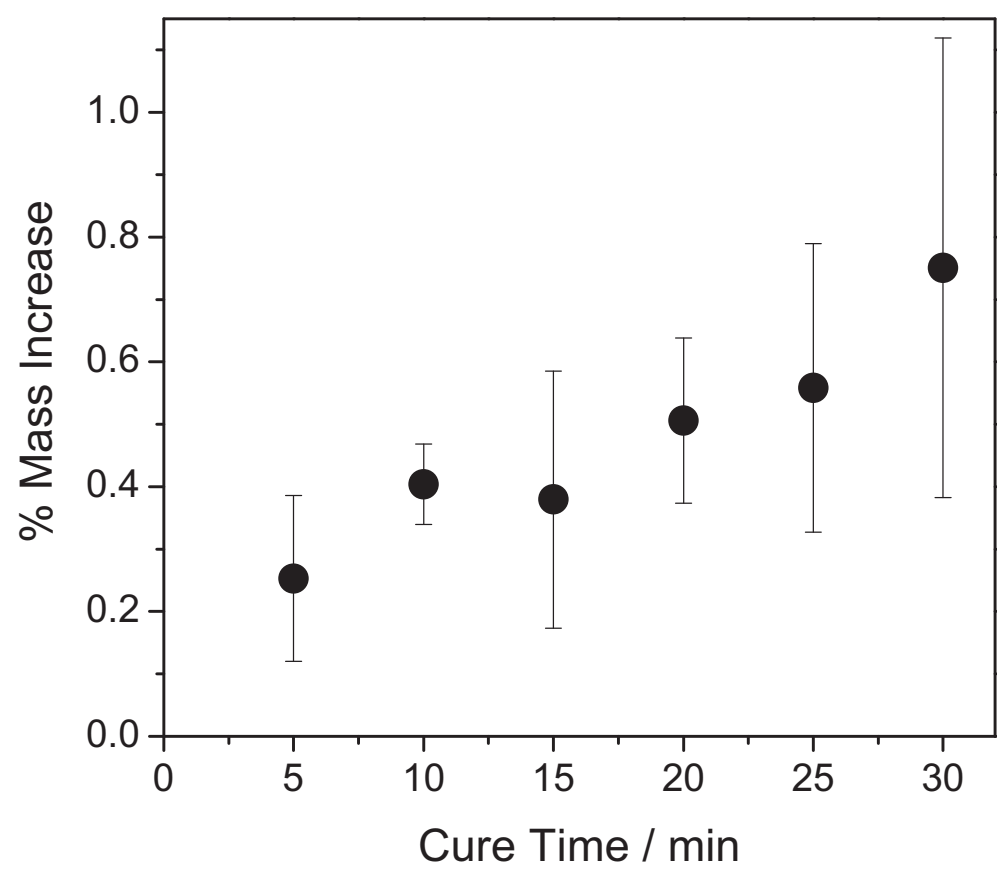

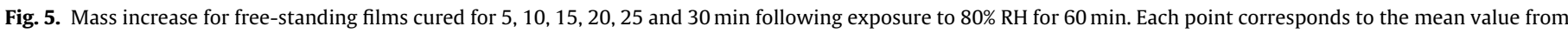
four experiments, error bars correspond to 1S.D.

typically highly-orientated, multiple bonded species. In the case of epoxy-phenolic resin, the hydroxyl groups available for hydrogen bonding with water exist within a rigid polymer network. Luo et al. [49] have previously reported that the mobility of epoxy polymer chains does not increase upon water sorption, indicating that rearrangement to accommodate multiple hydrogen bonds per water molecule is improbable. Moreover, given the small percentage of water adsorbed by these coatings, hydrogen bonding capability is considered weak, thus absorbance in this region more likely corresponds to clustered water residing in larger voids comprising the free volume. Therefore both dangling $\mathrm{OH}$ bonds and strongly hydrogen bonded species can be associated with 'free' water (not interacting with the resin). In contrast, the intermittent region at $3300-3500 \mathrm{~cm}^{-1}$ is characteristic of weak hydrogen

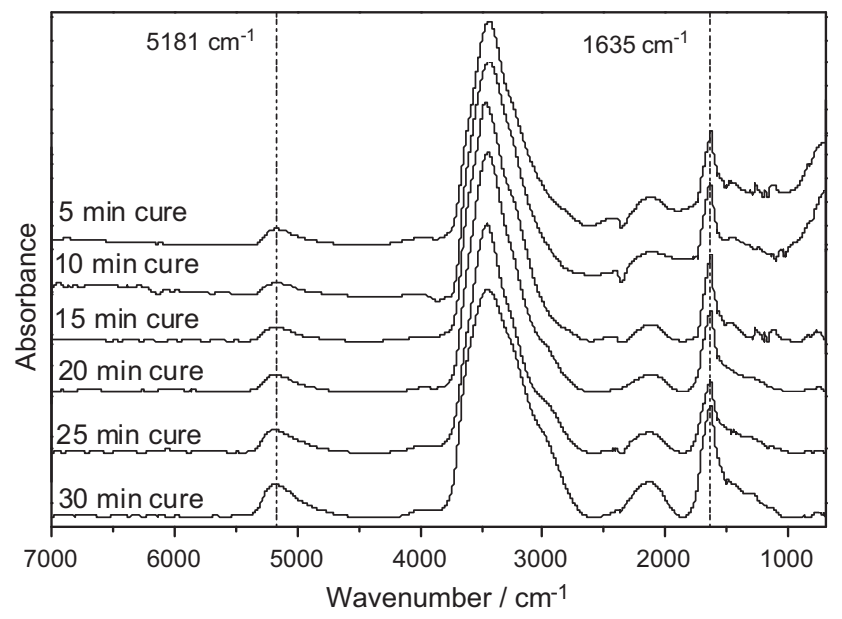

Fig. 6. Difference FTIR spectra for $5,10,15,20,25$ and 30 min cured epoxy phenolic films after exposure to $80 \%$ RH for $60 \mathrm{~min}$. Difference spectra were obtained by subtraction of spectra taken at 0.4 min exposure time. bonding, in line with the predicted weak interaction with the epoxy-phenolic resin.

Whilst the $\mathrm{OH}$ stretch absorbance evidently corresponds to a plethora of hydroxyl environments (i.e., water molecules forming single/multiple hydrogen bonds, behaving as donors/acceptors), for comparison between samples the absorbance can be modelled using a peak-fitting procedure, with Gaussian curves centred on $3627 \mathrm{~cm}^{-1}, 3496 \mathrm{~cm}^{-1}$ and $3383 \mathrm{~cm}^{-1}$, and $3255 \mathrm{~cm}^{-1}$, Fig. 7 [64]. Peak-fitting of the difference spectra obtained after $60 \mathrm{~min}$ exposure to humid conditions revealed that whilst the absolute absorbance varied, the ratio of fitted peaks were independent of sample cure time and water content $(21 \pm 3 \%, 24 \pm 3 \%, 42 \pm 3 \%$, and $13 \pm 2 \%$ area for peaks centred on $3255 \mathrm{~cm}^{-1}, 3383 \mathrm{~cm}^{-1}$ and $3496 \mathrm{~cm}^{-1}$, and $3627 \mathrm{~cm}^{-1}$ respectively). This indicates that the degree of hydrogen bonding for absorbed water is consistent across samples of differing cross-linking density.

Peak fitting was also performed at various time points during exposure of a 30 min cured sample. In this case the nature of the absorbed moisture was found to evolve during uptake $[43,64]$. Visual inspection of the $\mathrm{OH}$ stretch peak clearly shows that early spectra are dominated by the higher frequency $3627 \mathrm{~cm}^{-1} \mathrm{com}-$ ponent (indicative of a large contribution by dangling $\mathrm{OH}$ bonds), whereas at later times intermediate wavenumber absorbance dominates, corresponding to an increased proportion of weakly hydrogen bonded species, Figs. 7 and 8.

In addition to the discussed mid-infrared peaks, a further characteristic absorbance for water was observed in the near IR region at $5181 \mathrm{~cm}^{-1}$ (assigned to a combination of $\mathrm{OH}$ asymmetric stretch and deformation fundamentals), Fig. 6 [40-42]. This peak occurs in a region free from interference by resin absorbance, and therefore integration yields values directly proportional to water uptake, Figs. 9 and 10. In accordance with the procedure used for the mid IR region, the increase of absorbance at $5181 \mathrm{~cm}^{-1}$ was plotted, and the initial value was set to zero. Although the signal-to-noise ratio in this region of the spectrum is significantly poorer than in the mid-IR, the data confirms that more highly cured samples absorb more water. 

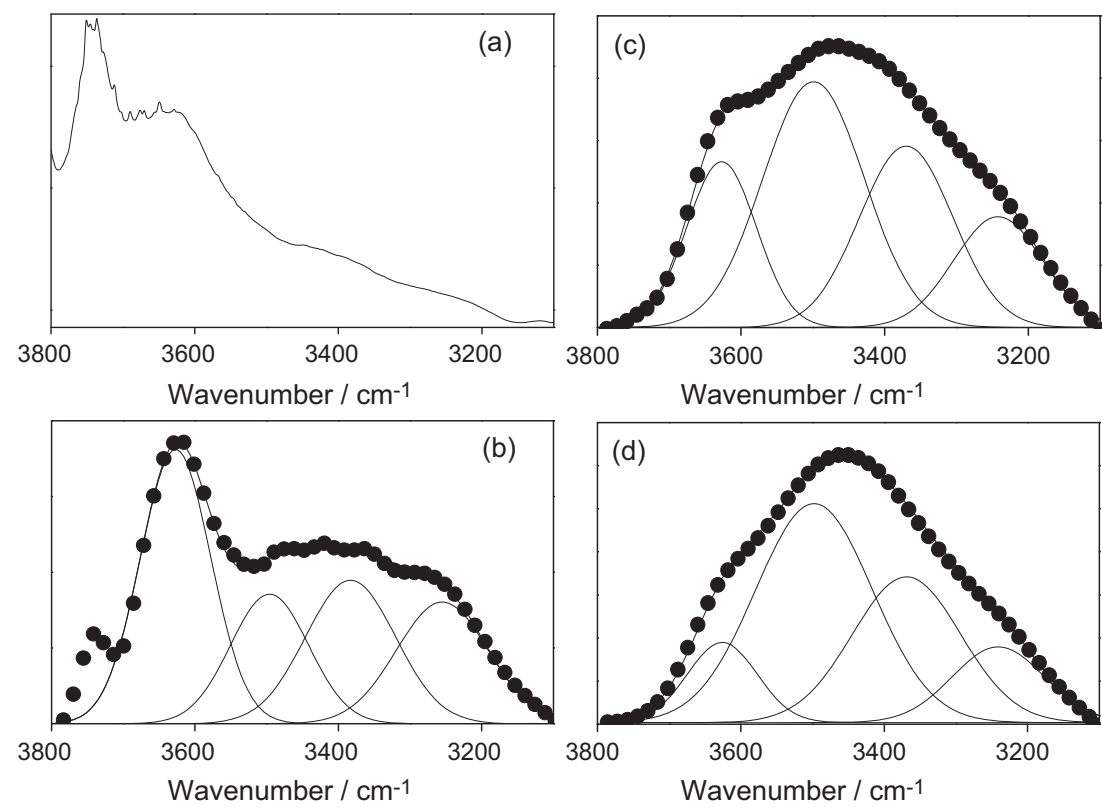

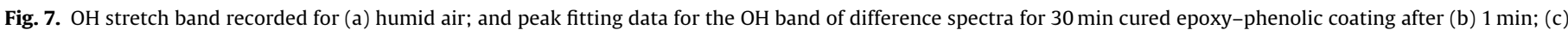
$10 \mathrm{~min}$ and (d) $30 \mathrm{~min}$ exposure to $80 \% \mathrm{RH}$.

\subsection{Resin softening}

In order to investigate the effect of water uptake on physical properties, nanomechanical measurements were performed using the atomic force microscope (AFM) under controlled humidity. Featureless $10 \mu \mathrm{m} \times 10 \mu \mathrm{m}$ regions were selected in order to monitor effects on the bulk polymer. Peak force nanomechanical measurements gave initial mean GMT moduli values of $664 \mathrm{MPa}$ and $969 \mathrm{MPa}$ for $10 \mathrm{~min}$ and $30 \mathrm{~min}$ cured samples respectively, Fig. 11. After $2 \mathrm{~h}$ exposure to a high humidity environment $(70 \%$ $\mathrm{RH}$ ) the 10 min cured sample was softened to a final mean value of $617 \mathrm{MPa}$ (average decrease of $47 \mathrm{MPa}$ ), in comparison to a final

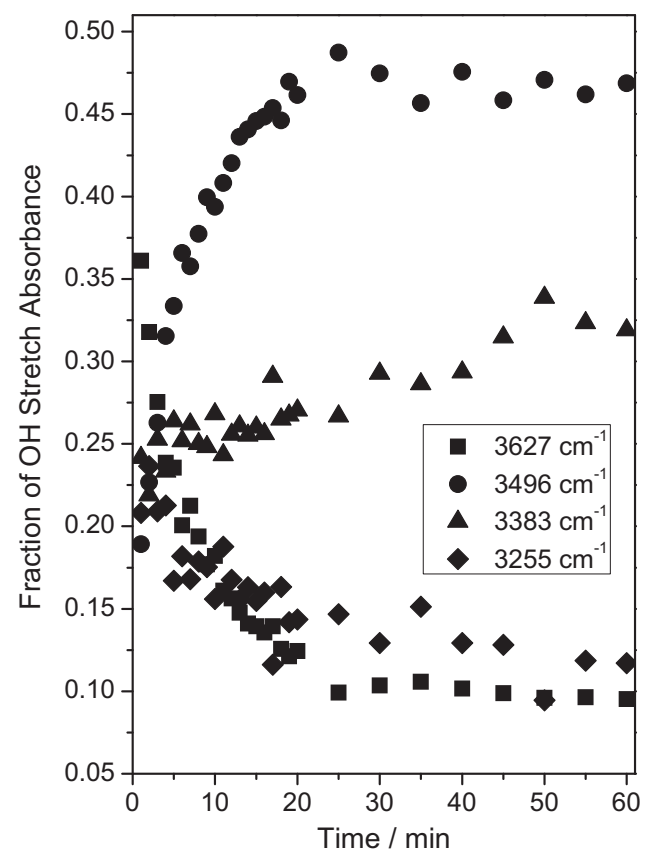

Fig. 8. Fitted peak areas as a fraction of the total $\mathrm{OH}$ stretch absorbance in difference spectra obtained for a $30 \mathrm{~min}$ cured epoxy phenolic coating as a function of exposure time to $80 \% \mathrm{RH}$.

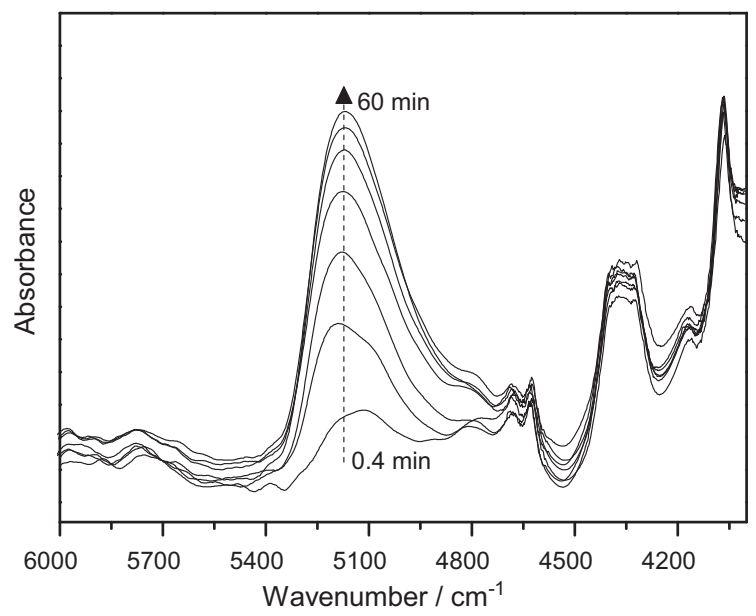

Fig. 9. Near IR spectra for $30 \mathrm{~min}$ cured Vitalure 345 lacquer after exposure to an $80 \% \mathrm{RH}$ environment for $0.4,10,20,30,40,50$ and $60 \mathrm{~min}$.

value of $465 \mathrm{MPa}$ for the 30 min cured sample (softened by an average of $504 \mathrm{MPa}$ ). This enhanced softening for the more highly cured resin supports increased water uptake.

\section{Discussion}

The effect of cure time on water sorption may be understood by considering the macromolecular architecture of resins. For highly cross-linked glassy network polymers, such as those investigated in the present study, macroscopic density is known to decrease with a greater degree of crosslinking $[61,62,65]$. It has been proposed that this occurs as a consequence of limited packing efficiency around crosslink sites [66,67]. An alternative explanation lies in the raised $T_{\mathrm{g}}$ of more highly cross-linked samples, meaning that these are farther from their equilibrium conformation when the structure is frozen on cooling $[68,69]$. Both entail greater amounts of frozen free volume for more highly cross-linked samples. Indeed, in the present case extended curing yields samples of increased thickness, which, taken alongside the consistent weight of the coating per unit area, is 


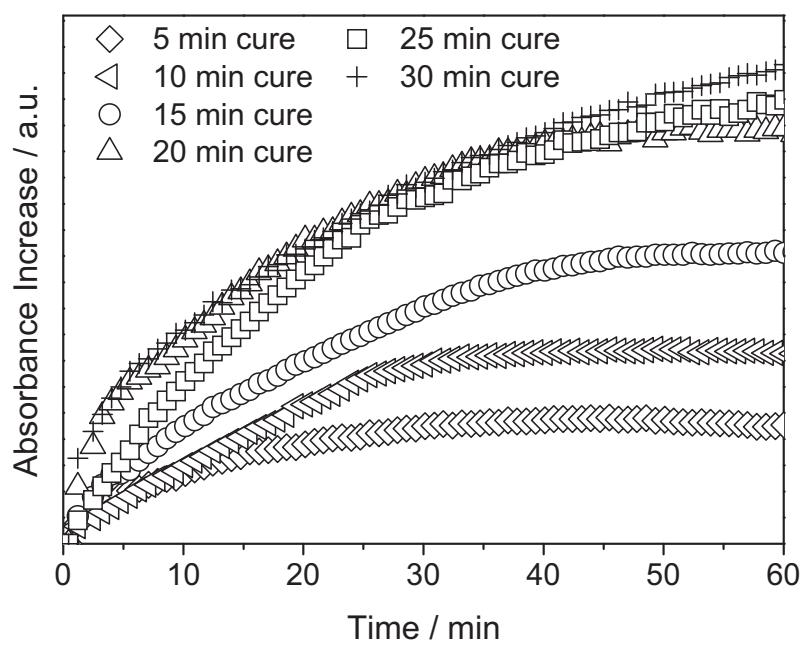

Fig. 10. Absorbance increase of the $5181 \mathrm{~cm}^{-1}$ band as a function of exposure time to $80 \%$ RH for epoxy-phenolic coatings cured for 5, 10, 15, 20, 25 and $30 \mathrm{~min}$. Each point represents the mean value obtained from five experiments.

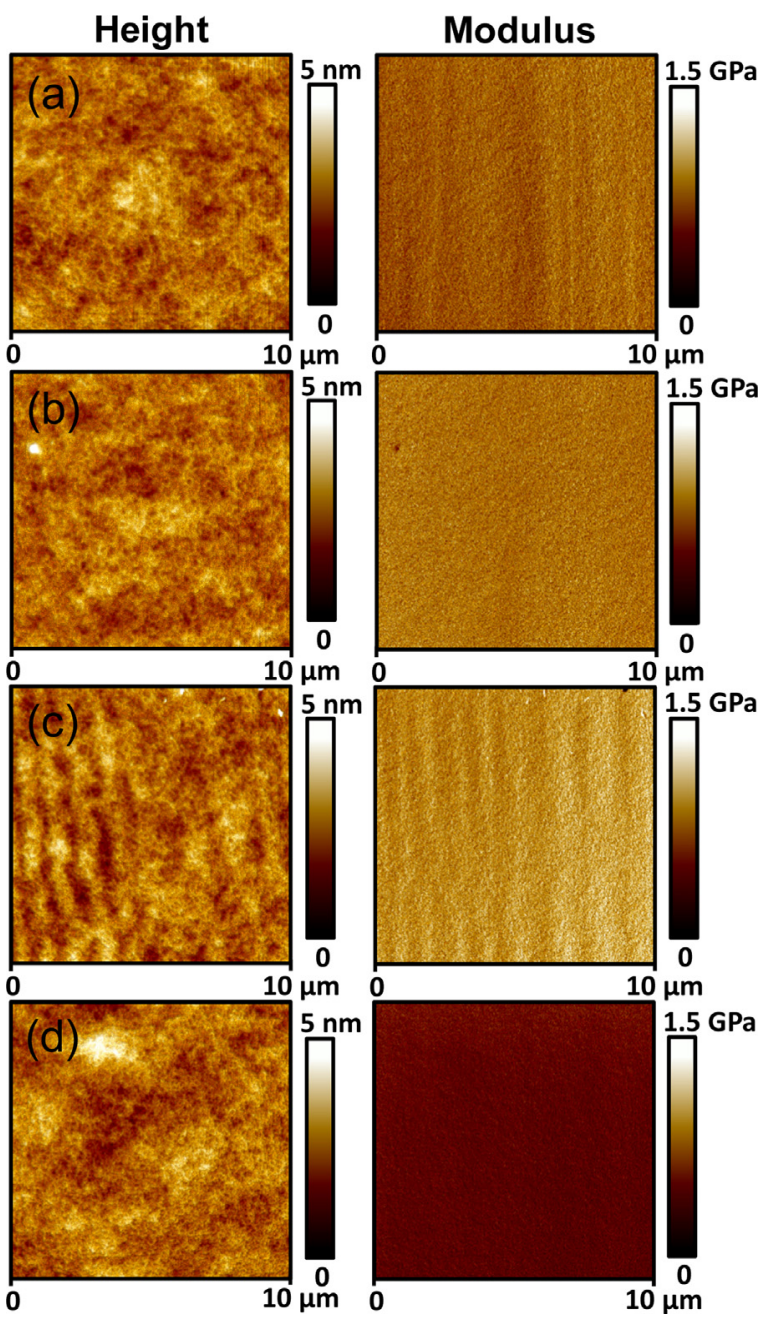

Fig. 11. Peakforce AFM topography and corresponding DMT modulus images for 10 min cured epoxy phenolic coating (a) before and (b) after $2 \mathrm{~h}$ exposure to $70 \%$ $\mathrm{RH}$; and 30 min cured epoxy phenolic coating (c) before and (d) after $2 \mathrm{~h}$ exposure to $70 \% \mathrm{RH}$. a strong indicator of reduced density and therefore greater free volume, Fig. 2. Systematic study of free volume effects in epoxy resins can be problematic, because strategies such as altering the chemical structure of the cross-linker often introduce a concurrent change in polarity, and thereby override the effects of free volume on water sorption [29]. In this study, the structure and ratio of the epoxy resin and phenolic cross-linker are conserved throughout, so that a negligible change in polarity is anticipated with cure time and this is borne out by the consistent water contact angles measured. Chemically, the epoxy-phenolic cure reaction involves the generation of an ether and secondary hydroxyl from the epoxy ether and primary hydroxyl of the reactants. These groups are of comparable hydrogen bonding capability, so the effect of unreacted chain ends on resin polarity is regarded as negligible. Equilibrium uptake therefore follows the increase in free volume (cross-linking), in agreement with previous studies detailing water absorption for epoxy resins in the absence of polarity effects [29-33].

Water contained in epoxy resins has previously been established by the FTIR peak fitting methodology to exist in several states. Both mid and near infrared peaks have been used to identify free, singly and doubly hydrogen bonded water within resins [39-43]. In this study, it is significant that regardless of cure time (i.e., the proportion of free volume) and equilibrium uptake, the degree of hydrogen bonding for absorbed water is found to be constant at equilibrium. This indicates that the hydrogen bonding sites available to water molecules scale with the available free volume. Apicella proposed that there are three modes of water absorption into resins; adsorption into the free volume, hydrogen bonding to sites located on the walls of microvoids comprising the free volume, and dissolution into the bulk resin [24]. Since the degree of hydrogen bonding for water is unchanged for more cross-linked samples (containing more free volume), it seems likely that hydrogen bonded water is associated with the free volume, rather than being dissolved into the bulk resin. Furthermore, if internal network hydrogen bonding was affected by water uptake (by dissolution into the bulk), the $\mathrm{OH}$ stretch absorbance associated with the resin would be expected to shift, resulting in derivative type features in difference spectra, and these are not observed, Figs. 6 and 7 [70]. From the spectroscopic evidence presented herein, it appears that water is primarily adsorbed into the free volume, where it attaches to hydrogen bonding sites available in the immediate vicinity.

A further important result obtained in this study is the changing nature of water during uptake. The mechanism proposed by Soles, whereby water transport occurs via free volume pathways to allow access to polymeric hydrogen bonding sites, predicts that adsorption of 'free' water should precede migration to hydrogen bonding sites, and this appears to be the case. The nature of water during uptake has been evaluated previously, with varied results. Musto et al. [40,41] and Wu et al. [59] have reported a slight decrease in the ratio of free to bound water with increasing moisture content, in agreement with the results presented here. However, in the case of an epoxy-phenolic network studied using 2D-ATR, Lui et al. [57] concluded that the absorption of bound water occurs prior to diffusion into the bulk. It is probable that the characteristics of water uptake are particular to the polymeric system studied, although an alternative explanation for this ambiguity lies in the ATR methodology used in the latter study to monitor water uptake. Limitations of this approach include the requirement of coating ATR crystals to ensure good contact with the resin, and an inherently limited sampling depth. For ATR, absorbed water is not detected until it has penetrated to the sampling depth of the evanescent wave. Initial uptake near the resin/water interface may therefore be overlooked, and this could be responsible for the early changes in the nature of adsorbed water observed here. An alternative methodology using transmission mode FTIR in a specially constructed cell was reported by Cotugno et al. $[43,64]$ where a free-standing film was prepared 
and monitored under controlled humidity. Using this approach, the contribution of free water was found to decrease with water activity in one case [64] and was found to be established immediately and remain unchanged in another [43]. In the present study, comparable results have been obtained using a simplified methodology, where a coated substrate is placed in a reflection cell and exposed to raised humidity. The advantages of such an approach comprise a sampling space inclusive of the entire film and a lack of specialist equipment.

Finally, whilst plasticisation of epoxy resins by sorbed water is a widely acknowledged phenomenon, the mechanism of polymer softening is not fully understood. It has been proposed that only 'bound' water plasticises polymers by disruption of the polymeric hydrogen bonding network [40]. In the present case, however, whilst FTIR evidence has been presented for hydrogen bonding between adsorbed moisture and the polymer, no evidence for disruption of network hydrogen bonding has been found. As resins are shown to be softened by water uptake, it appears that softening can be induced by water associated with the free volume.

\section{Conclusions}

Water uptake by epoxy resins has previously been shown to depend on free volume. An epoxy-phenolic can coating spin cast from a complex industrial formulation was shown to adhere to this relationship, where water uptake is dependent on the degree of cross-linking (cure time), rather than the presence of additives. FTIR analysis confirmed the presence of bound water (hydrogen bonded to the resin) and non-interacting water, where the proportion of bound water increases during uptake.

\section{Acknowledgment}

S. Morsch would like to thank AkzoNobel for materials and financial support.

\section{References}

[1] A. Toldy, B. Szolnoki, Gy. Marosi, Polym. Degrad. Stab. 96 (2011) 371-376.

[2] G. Williams, R. Trask, I. Bond, Composites Part A 38 (2007) 1525-1532.

[3] J. Njuguna, K. Pielichowski, Adv. Eng. Mater. 5 (2003) 769-778.

[4] B. Chen, M. Guizar-Sicairos, G. Xiong, L. Shemilt, A. Diaz, J. Nutter, N. Burdet, S. Huo, J. Mancuso, A. Monteith, F. Vergeer, A. Burgess, I. Robinson, Sci. Rep. 3 (2013) 1177.

[5] P. Rafiee, G. Khatibi, N. Nelhiebel, R. Pelzer, Microelectron. Reliab. 53 (2013) 1563-1567.

[6] C. Zhang, J. Hankett, Z. Chen, ACS Appl. Mater. Interfaces 4 (2012) 3730-3737.

[7] J.E. White, H.C. Silvis, M.S. Winkler, T.W. Glass, D.E. Kirkpatrick, Adv. Mater. 12 (2000) 1791-1800,

[8] G. Lendvay-Győrik, T. Pajkossy, B. Lengyel, Prog. Org. Coat. 59 (2007) 9599.

[9] V.A. Sytov, A.E. Verstakov, A.E. Voronin, Polym. Sci. Ser. D 6 (2013) 116-119.

[10] T.S. Jesperspen, J. Nygård, Appl. Phys. Lett. 90 (2007) 183108-1-183108-3.

[11] B.R. Jackson, X. Liu, E.F. McCandlish, R.E. Riman, Langmuir 23 (2007) 11399-11403

[12] P. Mani, A.K. Gupta, S. Krishnamoorthy, Int. J. Adhes. Adhes. 7 (1987) 157-163.

[13] J.K. Lancaster, Wear 14 (1969) 223-239.

[14] A. Wegmann, Prog. Org. Coat. 32 (1997) 231-239.

[15] S.-Y. Zhang, Y.-F. Ding, S.-J. Li, X.-W. Luo, W.-F. Zhou, Corros. Sci. 44 (2002) $861-869$

[16] S.-Y. Zhang, S.-J. Li, X.-W. Luo, W.-F. Zhou, Corros. Sci. 42 (2000) 2037-2041.

[17] M.C.S.S. Macedo, I.C.P. Margarit-Mattos, F.L. Fragata, J.-B. Jorcin, N. Pébère, O.R. Mattos, Corros. Sci. 51 (2009) 1322-1327.
[18] X. Zhang, Q. He, H. Gu, H.A. Colorado, S. Wei, Z. Guo, ACS Appl. Mater. Interfaces 5 (2013) 898-910.

[19] L.-H. Lee, J. Polym. Sci. A: Gen. Pap. 3 (1965) 859-882.

[20] G.Z. Xiao, M.E.R. Shanahan, Polymer 39 (1998) 3253-3260.

[21] A.F. Abdelkader, J.R. White, J. Mater. Sci. 40 (2005) 1843-1854

[22] G.Z. Xiao, M.E.R. Shanahan, J. Polym. Sci. B: Polym. Phys. 35 (1997) 2659-2670

[23] M.K. Antoon, J.L. Koenig, J. Polym. Sci. Polym. Phys. Ed. 19 (1981) 197-212.

[24] A. Apicella, R. Tessieri, C. De Cataldis, J. Membr. Sci. 18 (1984) 211-225.

[25] R.F. Fedors, Polymer 21 (1980) 713-715.

[26] A. Chateauminois, B. Chabert, J.P. Soulier, L. Vincent, Polym. Compos. 16 (1995) 288-296.

[27] P. Moy, F.E. Karasz, Polym. Eng. Sci. 20 (1980) 315-319.

[28] J. Li, C.S. Jeffcoate, G.P. Bierwagen, D.J. Mills, D.E. Tallman, Corrosion 54 (1998) $763-771$

[29] M. Jackson, M. Kaushik, S. Nazarenko, S. Ward, R. Maskell, J. Wiggins, Polymer 52 (2011) 4528-4535.

[30] C.L. Soles, F.T. Chang, B.A. Bolan, H.A. Hristov, D.W. Gidley, A.F. Yee, J. Polym. Sci. B: Polym. Phys. 36 (1998) 3035-3048.

[31] C.L. Soles, F.T. Chang, D.W. Gidley, A.F. Yee, J. Polym. Sci. B: Polym. Phys. 38 (2000) 776-791.

[32] C.L. Soles, A.F. Yee, J. Polym. Sci. B: Polym. Phys. 38 (2000) 792-802.

[33] M.T. Aronhime, X. Peng, J.K. Gillham, R.D. Small, J. Appl. Polym. Sci. 32 (1986) 3589-3626.

[34] Y. Ding, M. Liu, S. Li, S. Zhang, W.-F. Zhou, B. Wang, Macromol. Chem. Phys. 202 (2001) 2681-2685.

[35] J. Wang, J. Gong, Z. Gong, X. Yan, B. Wang, Q. Wu, S. Li, Nucl. Instrum. Methods Phys. Res. Sect. B 268 (2010) 2355-2361.

[36] L. Li, M. Liu, S. Li, Polymer 45 (2004) 2837-2842.

[37] L. Li, S. Zhang, Y. Chen, M. Liu, Y. Ding, X. Luo, Z. Pu, W. Zhou, S. Li, Chem. Mater. 17 (2005) 839-845

[38] L. Li, Y. Yu, Q. Wu, G. Zhan, S. Li, Corros. Sci. 51 (2009) 3000-3006.

[39] Y. Ngono, Y. Maréchal, N. Mermilliod, J. Phys. Chem. B 103 (1999) 4979-4985.

[40] P. Musto, G. Ragosta, G. Scarinzi, L. Mascia, J. Polym. Sci. B: Polym. Phys. 40 (2002) 922-938.

[41] P. Musto, G. Ragosta, L. Mascia, Chem. Mater. 12 (2000) 1331-1341.

[42] J. Mijovic, H. Zhang, Macromolecules (2003) 1279-1288.

[43] S. Cotugno, G. Mensitieri, P. Musto, L. Sanguigno, Macromolecules 38 (2005) $801-811$.

[44] J. Mijovic, H. Zhang, J. Phys. Chem. B 108 (2004) 2557-2563.

[45] I.D. Maxwell, R.A. Pethrick, J. Appl. Polym. Sci. 28 (1983) 2363-2379.

[46] C. Grave, I. McEwan, R. Pethrick, J. Appl. Polym. Sci. 69 (1998) 2369-2376.

[47] D. Hayward, E. Hollins, P. Johncock, I. McEwan, R.A. Pethrick, E.A. Pollock, Polymer 38 (1997) 1151-1168

[48] J. Gonzalez-Benito, J. Bravo, F. Mikes, J. Baselga, Polymer 44 (2003) 653-659.

[49] S. Luo, J. Leisen, C.P. Wong, J. Appl. Polym. Sci. 85 (2002) 1-8.

[50] J. Zhou, J.P. Lucas, Polymer 40 (1999) 5513-5522.

[51] G.D. Shay, K.R. Olesen, J.L. Stallings, J. Coat. Technol. 68 (1996) 51-63.

[52] B.J. Roulstone, M.C. Wilkinson, J. Hearn, Polym. Int. 27 (1992) 43-50.

[53] J.E. Hanle, E.H. Merz, R.B. Mesrobian, J. Polym. Sci. C: Polym. Symp. 12 (1966) 185-195.

[54] E.L. Bradley, M. Driffield, N. Harmer, P.K.T. Oldring, L. Castle, Int. J. Polym. Anal. Charact. 13 (2008) 200-223.

[55] T. Suzuki, Y. Oki, M. Numajiri, T. Miura, K. Kondo, Y. Shiomi, Y. Ito, J. Appl. Polym. Sci. 49 (1993) 1921-1929.

[56] T. Suzuki, Y. Oki, M. Numajiri, T. Miura, K. Kondo, Y. Shiomi, Y. Ito, Polymer 37 (1996) 3025-3030.

[57] M. Liu, P. Wu, Y. Ding, G. Chen, S. Li, Macromolecules (2002) 5500-5507.

[58] M. Liu, P. Wu, Y. Ding, S. Li, Phys. Chem. Chem. Phys. 5 (2003) 1848-1852.

[59] P. Wu, H.W. Siesler, Chem. Phys. Lett. 374 (2003) 74-78.

[60] M. Wojdyr, J. Appl. Crystallogr. 43 (2010) 1126-1128.

[61] V.B. Gupta, C. Brahatheeswaran, Polymer 32 (1991) 1875-1884

[62] K.P. Pang, J.K. Gillham, J. Appl. Polym. Sci. 37 (1989) 1969-1991.

[63] D. Lin-Vien, N.B. Colthup, W.G. Fateley, J.G. Grasselli, The Handbook of Infrared and Raman Characteristic Frequencies of Organic Molecules, Academic Press Ltd., London, 1991.

[64] S. Cotugno, D. Larobina, G. Mensitieri, P. Musto, G. Ragosta, Polymer 42 (2001) 6431-6438.

[65] V.B. Gupta, L.T. Drzal, C.Y.-C. Lee, M.J. Rich, Polym. Eng. Sci. 25 (1985) 812-823.

[66] Y.G. Won, J. Galy, J.P. Pascault, J. Verdu, Polymer 32 (1991) 79-83.

[67] R.J. Morgan, F.-M. Kong, C.M. Walkup, Polymer 25 (1984) 375-386.

[68] V.B. Gupta, L.T. Drzal, C.Y.-C. Lee, M.J. Rich, J. Macromol. Sci. B: Phys. B23 (1984) 435-466.

[69] J.B. Enns, J.K. Gillham, J. Appl. Polym. Sci. 28 (1983) 2831-2846.

[70] P. Musto, G. Ragosta, G. Mensitieri, M. Lavorgna, Macromolecules 40 (2007) 9614-9627. 